achieve this good condition. The amount of patients on medication emphasize the need of the structured transition.

References:

[1] Minden K, Niewerth M, Muther S: [Berlin transition program: from adolescents to adults in rheumatology treatment]. Z Rheumatol 2014, 73(6):526-531.

Disclosure of Interest: None declared

DOI: 10.1136/annrheumdis-2017-eular.3171

\section{AB0972 CHILDHOOD ONSET STROKE AND VASCULITIS ASSOCIATED WITH DEFICIENCY OF ADENOSINE DEAMINASE 2 (DADA2)}

V. Paisal ${ }^{1}$, E. Al-Abadi ${ }^{1}$, T. Southwood ${ }^{1}$, E. Wassmer ${ }^{2}$. ${ }^{1}$ Paediatric Rheumatology; ${ }^{2}$ Paediatric Neurology, Birmingham Children's Hospital, Birmingham, United Kingdom

Background: The deficiency of Adenosine Deaminase 2 (DADA2) is a rare autosomal recessive condition resulting from mutations in CECR1 (Cat Eye Syndrome Chromosome Region 1) gene, mapped to chromosome 22q11.1. It is a type of autoinflammatory disease, mainly characterised by early-onset polyarteritis, haemorrhagic, ischemic strokes and hypogammaglobulinemia (1). We report a case of 7-year boy presenting with haemorrhagic stroke and vasculitis responding to immunosuppression with Anti-TNF drug.

Objectives: A 7 year boy presented to the emergency department with reduced consciousness, headaches and nose bleeds. Initial imaging showed an intraparenchymal haemorrhage requiring frontal craniotomy and evacuation of the haematoma. This acute presentation was preceded by a history of recurrent fevers, weight loss, testicular pain, erythema nodosum and tender lymph nodes. Methods: The laboratory findings revealed anaemia, ESR of up to $61 \mathrm{~mm} / \mathrm{h}$, C-reactive protein 100, normal immunoglobulins, positive Anti nuclear antibody (ANA), mildly raised antibodies to double stranded DNA (dsDNA) and Proteinase 3 antibody. Skin biopsy confirmed panniculitis. CT imaging and angiography of the head at the time of acute presentation showed intraparenchymal haemorrhage and aneurysm of the left middle cerebral artery. Further CT angiography of the whole body revealed renal and liver microaneurysms. A provisional diagnosis of Polyarteris nodosa was made and started on steroids and cyclophosphamide. He had further genetic testing, showing mutation in CECR1, leading to Adenosine deaminase 2 deficiency. Patient responded to cyclophosphamide induction regime, which was followed by Etanercept.

Results: We report a case of ADA2 deficiency presenting initially with features of an autoinflammatory disorder, complicated by acute stroke secondary to haemorrhage. Our patient exhibited most of the clinical symptoms previously reported in ADA2 deficiency, including its association with polyarteritis nodosa (2). Although, he did not exhibit hypogammaglobulinaemia (3) which has been reported, interestingly, he was positive for markers of autoimmunity (ANA, ANCA) (4). It has been reported that treatment with anti-TNF and IL-6 (5) could lead to improvement, and our patients initial response to cyclophosphamide was excellent, followed by continued treatment with Etanercept.

Conclusions: Screening for adenosine deaminase 2 deficiency should be considered in all children presenting with neurological symptoms and features of vasculitis.

References:

[1] Roberta Caorsi, Federica Penco, Francesca Schena and Marco Gattorno. Monogenic polyarteritis: the lesson of ADA2 deficiency.Pediatric Rheumatology 2016. DOI: 10.1186/s12969-016-0111-7.

[2] Nanthapisal S, Murphy C, Omoyinmi E, Hong Y, Standing, A, Berg S, Ekelund M, Jolles S, Harper L, Youngstein T, Gilmour K, Klein N, Eleftheriou D, Brogan PA. Deficiency of adenosine deaminase type 2 (DADA2): a description of phenotype and genotype in 15 cases. Arthritis and Rheumatism.

[3] Segel R, King MC, Levy-Lahad E. Mutant ADA2 in vasculopathies. N Engl J Med 2014;371:481-2. doi:10.1056/NEJMc1407114.

[4] Zhou Q, Yang D, Ombrello AK et al. Early-onset stroke and vasculopathy associated with mutations in ADA2. N Engl J Med 2014;370:911-20. doi:10.1056/NEJMoa1307361

[5] Van Eyck L, Liston A, Wouters C. Mutant ADA2 in vasculopathies. N Engl J Med 2014;371:480 doi:10.1056/NEJMc1405506\#SA4

Disclosure of Interest: None declared

DOI: 10.1136/annrheumdis-2017-eular.5098

\section{AB0973 ANTIPHOSPHOLIPID ANTIBODIES IN CHILDREN WITH SYSTEMIC LUPUS ERYTHMATOSUS AND JUVENILE IDIOPATHIC ARTHRITIS}

W. Gouda ${ }^{1}$, A. Mohamed ${ }^{2} .{ }^{1}$ Rheumatology, Aswan University, Aswan; ${ }^{2}$ Pediatrics, Mansoura Univeristy, Mansoura, Egypt

Background: Antiphospholipid antibodies (aPL) are a family of autoantibodies that present in a small percentage of the population but occur more commonly in patients with Antiphospholipid syndrome (APS) and Systemic lupus erythematosus (SLE).

Objectives: We aimed to determine of the level of anti- $\beta 2$-glycoprotein I (anti-B2GPI) (IgG and $\operatorname{lgM}$ ) isotypes and anticardiolipin antibodies (aCL) as inflammatory markers in children with SLE and Juvenile Idiopathic Arthritis (JIA) and figure out their relation to the clinical manifestations and activity of the disease.
Methods: This prospective study included one hundred twenty children, sixty five having SLE and fifty five having JIA, their ages range between $4.5-16$ years ( 37 males and 83 females). In addition, twenty apparently healthy children of comparable age, sex and nutritional status were used as a control group. All patients and normal controls were subjected to full clinical and laboratory investigations included $\mathrm{aCL}$ and anti- $\beta 2 \mathrm{GPI}$ level (IgG and $\operatorname{lgM}$ ) measured by a standardized ELISA.

Results: IgG isotype of anti-p2GPI was found to be positive in $27.7 \%$ and $14.5 \%$ for SLE and JIA groups respectively. However IgM isotype of anti- $\beta 2$ GPI was found to be positive in $24.6 \%$ and $7.25 \%$ for SLE and JIA groups respectively. The mean levels of both IgG and IgM isotypes of anti- $\beta 2 \mathrm{GPI}$ were found to be significantly increased in comparison to controls $(P<0.001)$ in both SLE and JIA groups. IgG isotype of aCL was found to be positive in $23.1 \%$ and $18.2 \%$ for SLE and JIA groups respectively. However IgM isotype of aCL was found to be positive in $18.5 \%$ and $18.2 \%$ for SLE and JIA groups respectively. A significant positive correlation was found between $\operatorname{lgM}$ and $\lg \mathrm{G}$ isotypes of anti- $\beta 2 \mathrm{GPI}$ and with their corresponding class of aCL in both SLE and JIA groups. A significant positive correlation was found between the elevation of anti- $\beta 2 \mathrm{GPI}$ (IgG) and thrombocytopenia together with neuropsychiatric disease in SLE. While in JIA elevation of anti- $\beta 2 \mathrm{GPI}$ was found to be correlated only with elevation of $\mathrm{aCL}$ irrespective to clinical or laboratory data.

Conclusions: The study reported a higher prevalence of $\mathrm{APL}$ in children with SLE and JIA. Elevated levels of anti- $\beta 2 \mathrm{GPI}(\operatorname{lgG})$ correlated with thrombocytopenia together with neuropsychiatric disease in SLE.

Disclosure of Interest: None declared

DOI: 10.1136/annrheumdis-2017-eular.1593

\section{AB0974 ETANERCEPT TREATMENT FOR A PATIENT WITH REFRACTORY MACROPHAGE ACTIVATION SYNDROME IN JUVENILE SYSTEMIC LUPUS ERYTHEMATOUS}

Y. Ramirez, T. Díaz, R. Maldonado, E. Faugier, A.V. Villarreal, N. Acevedo on behalf of Pediatric Rheumatology. Hospital Infantil de México Federico Gómez, Mexico City, Mexico

Background: Macrophage activation syndrome (MAS) is a serious, potentially fatal complication of childhood systemic inflammatory disorders, and it is most frequent in Systemic Juvenile Idiopthic Arthritis, for instance, it is increasingly reported in other pediatric rheumatic diseases as lupus erythematosus and Kawasaki disease.

Objectives: To describe clinical case report of a 16 year old girl with Juvenil Systemic Lupus Erythematosus and Macrophage Activation Syndrome refractory. Methods: A 16-year-old woman with recent diagnosis of Systemic Lupus Erythematosus in November 2015. At admission with continuos fever lasting 2 months, with initial laboratory studies with Triglycerides $395 \mathrm{mg} / \mathrm{dl}$, Ferritin 3.300 ug/l, soluble receptor IL-2 $2.838 \mathrm{U} / \mathrm{ml}$, fibrinogen $166 \mathrm{mg} / \mathrm{dl}$, Hemophagocytos in bone marrow, presence of persistent cytopenias. Initial management with methylprednisolone $30 \mathrm{mg} / \mathrm{kg} /$ day (3 days) without clinical response was initiated. Management is added to Cyclosporin A (10 mg/kg/day), reporting subtherapeutic serum levels despite high doses without clinical response and improvement of laboratory controls. During the hospital stay complete 13 weeks of treatment with Etposide (180 mg/dose), with ferritin levels in 4,180 ug/l, triglycerides 438, Fibrinogen $455 \mathrm{mg} / \mathrm{dl}$, WBC 5,000 ul-1 (3,400 neutrophils, lymphocytes 1,050$)$, platelet count $78 \times 103 \mathrm{ml}^{-1}$, hemoglobin $7.2 \mathrm{~g} / \mathrm{dl}$. After three months of treatment, she was given with Etanercept $0.4 \mathrm{mg} / \mathrm{kg} / \mathrm{dose}, 2$ times a day. Currently in week 3 of treatment with WBC $6,500 \mathrm{ml}^{-1}$, hemoglobin $9.7 \mathrm{~g} / \mathrm{dl}$, platelet count $140 \mathrm{x}$ $103 \mathrm{ml}^{-1}$ and ferritin $4,270 \mathrm{ng} / \mathrm{ml}$. The patient remains disease with costicosteroid, cyclosporine, and etanercept, without adverse events.

Results: Patient treated with Etanercept during 5 weeks, presenting clinical response for MAS.

Conclusions: A general therapeutic protocol for MAS is not available: first line treatment is usually represented by parenteral administration of high dose corticosteroids. Mild forms are reported to respond to steroids alone in association with supportive medicaments. Steroid-resistant cases or the most severe forms of MAS require the addition of cyclosporine $A$, other therapeutic regimens have been studied such as high-dose intravenous immunoglobulins, antithymocyte globulins, etanercept, etoposide and plasmapheresis

References:

[1] Takahashi, N., Naniwa, T., \& Banno, S. (2008). Successful use of etanercept in the treatment of acute lupus hemophagocytic syndrome. Modern Rheumatology, 18(1), 72-75.

[2] Cron, R. Q., Davi, S., Minoia, F., \& Ravelli, A. (2015). Clinical features and correct diagnosis of macrophage activation syndrome. Expert review of clinical immunology, 11(9), 1043-1053.

[3] Bracaglia, C., Prencipe, G., \& De Benedetti, F. (2017). Macrophage Activation Syndrome: different mechanisms leading to a one clinical syndrome. Pediatric Rheumatology, 15(1), 5.

Disclosure of Interest: None declared

DOI: 10.1136/annrheumdis-2017-eular.5636 